
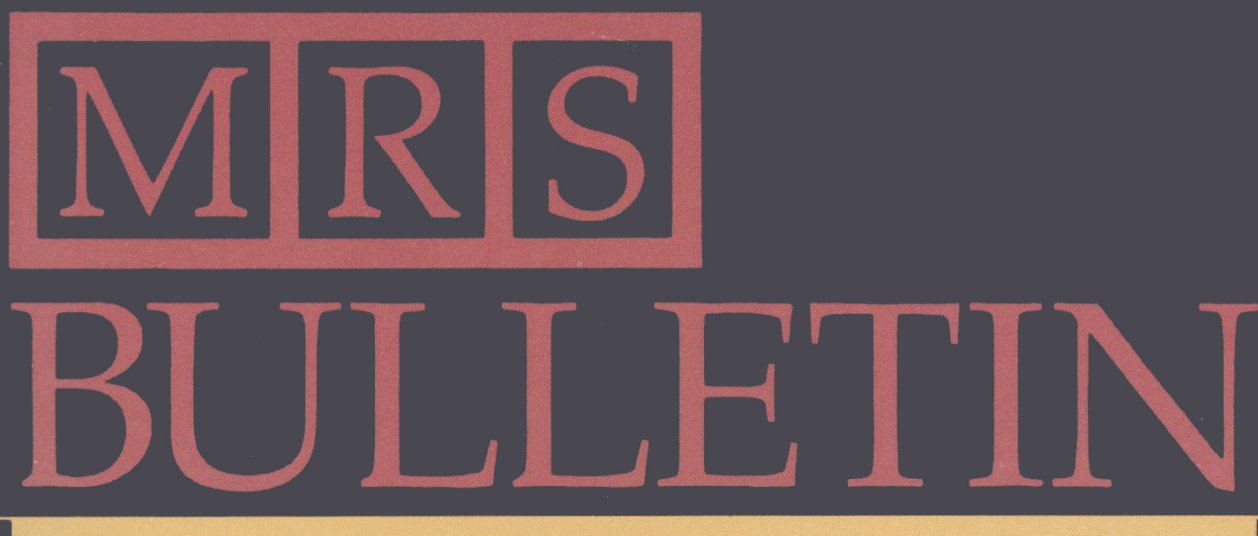

February 1990

Volume XV, Number 2

Serving the International Materials Research Community

\title{
Multilayer Materials
}

Low Magnification Showing Overall Structure

Magnification: $540,000 X$

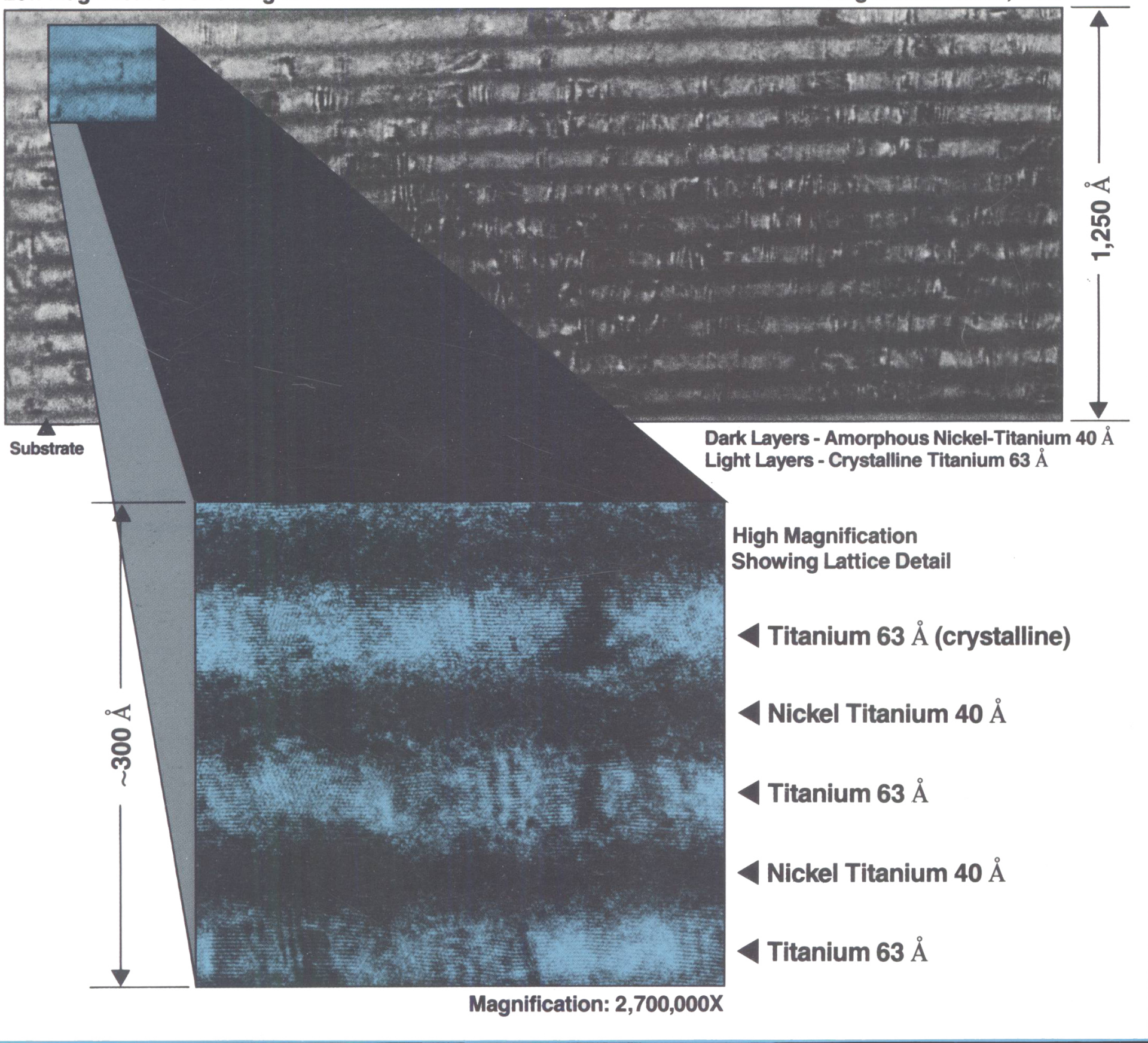




\section{$A N E W$ CLUSTER ISBORN}
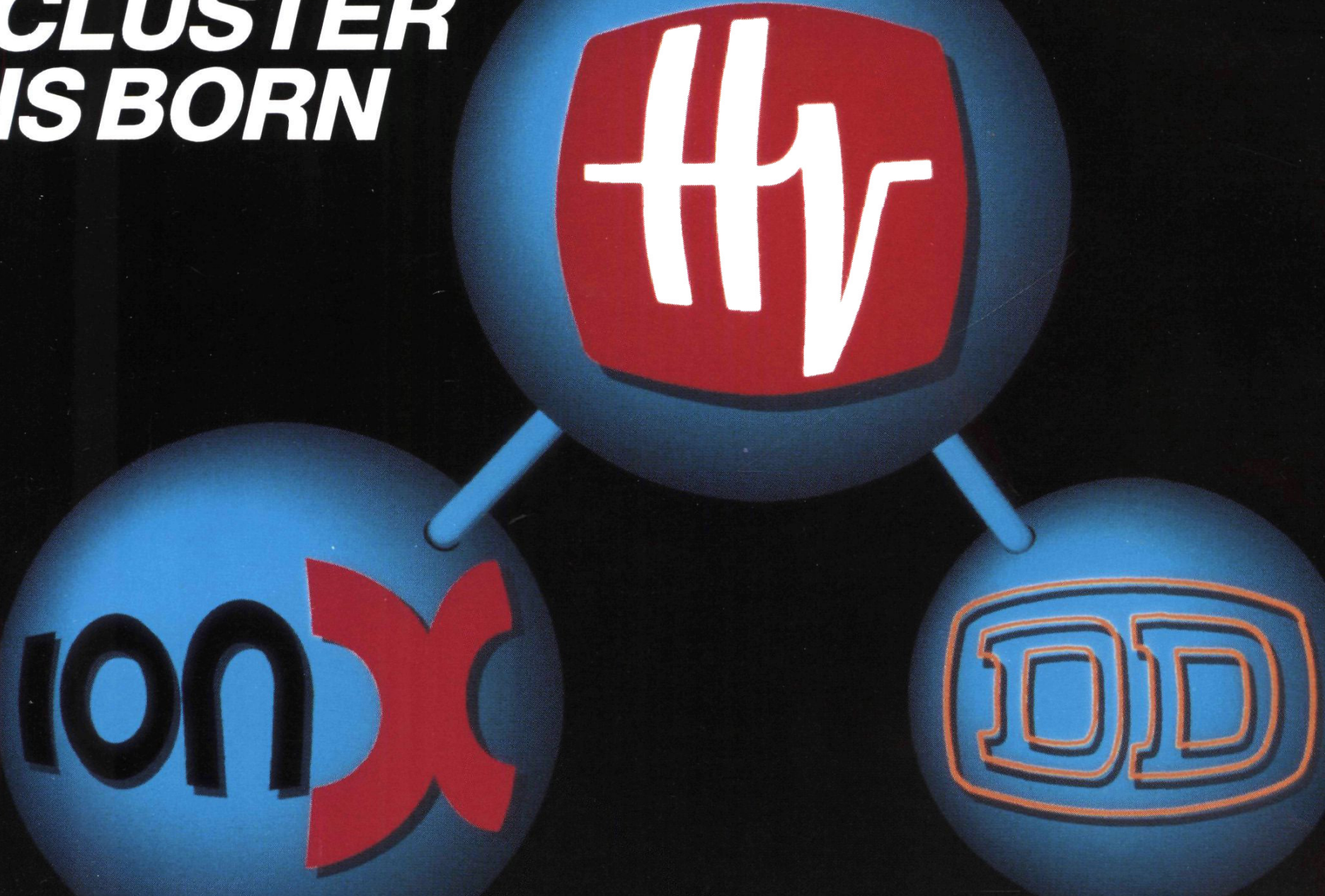

\section{General lonex acquired by High Voltage Engineering Europa B.V.}

In December 1987 High Voltage Engineering Europa B.V.

(HVEE) acquired Dowlish Developments Ltd (DD), an accelerator tube manufacturer located in the United Kingdom.

On April 10, 1989, HVEE purchased the General lonex Analytical Product Group from Genus Inc. based in the United

States.

Through this acquisition HVEE positions itself as the largest and most diverse manufacturer of particle accelerators for the scientific and industrial research communities.

The acquired General lonex (GI) product lines, which include

the Tandetron accelerator systems and Model 4175 RBS Analyser, will be manufactured in HVEE's new, well-equipped facility in Amersfoort, The Netherlands.

World wide marketing of all products from HVEE, DD and GI will originate from HVEE Amersfoort with sales and service offices in the USA, Europe and Japan.
After addition of the newly acquired products HVEE's product lines include:

- Ion Accelerator Systems

- Air insulated accelerators up to $500 \mathrm{kV}$

- Single ended Van de Graaff accelerators up to 4 MV

- Tandem Tandetron accelerators up to 3 MV/TV

- Research ion implanters

- Beam energies $10 \mathrm{keV}-9 \mathrm{MeV}$ and higher

- Systems for ion beam analysis

- Systems for RBS, PIXE, PIGE, NRA, ERD, MACS and MEIS

- Components

- HV power supplies, electron and ion accelerator tubes, ion sources beamline components, beam monitoring equipment, UHV sample manipulators, etc.

For further information on this transaction and product literature please contact HVEE in Amersfoort/NL. 
A Publication of the Materials Research Society Volume XV, Number 2 ISSN: 08837694 CODEN: MRSBEA

MULTILAYER MATERIALS

17 Multilayer Materials Troy W. Barbee Jr., Guest Editor

19 Metastable Phase Formation in Thin Films and Multilayers

Bruce M. Clemens and Robert Sinclair

29 Artificially Layered Superconductors

Ivan K. Schuller, J. Guimpel, and Y. Bruynseraede

37 Multilayer Optics for the Soft X-Ray and Extreme Ultraviolet

Troy W. Barbee Jr.

\section{SPECIAL FEATURE}

63 Upclose: Center for Advanced Materials Processing at Clarkson University

S.K. Ellis and E.P. McNamara Jr.

\section{MRS NEWS}

46 Preview: 1990 Spring Meeting

53 Chianelli Assumes MRS Presidency in 1990

56 Boston Meeting Attracts Worldwide Audience

61 Paul Siffert Receives Woody Award

61 Graduate Student Award Winners Honored at Fall Meeting

62 MRS Council Meets in Boston

\section{DEPARTMENTS}

4 Material Matters

7 Research/Researchers

12 Research Resources

15 From Washington

16 Editor's Choice

66 Historical Note

68 Section News

69 Chapter News

72 Book Reviews

73 Advertisers in this Issue

74 Calendar

78 Classified

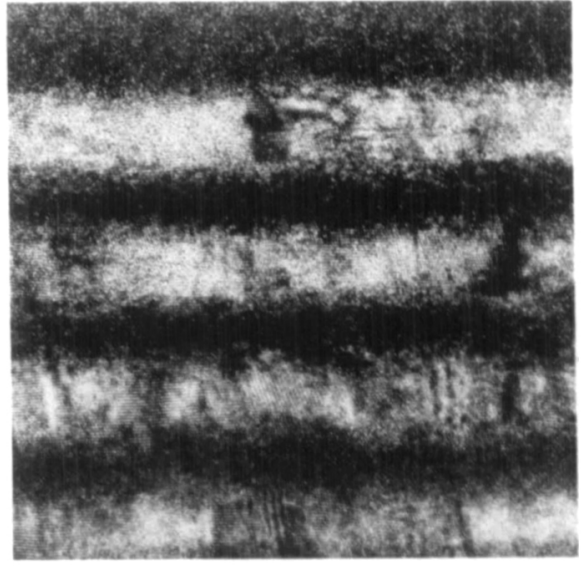

ON THE COVER: Transmission electron lattice image of a titanium (Ti) - nickel titanium (NiTi) multilayer synthesized by magnetron sputtering. The multilaver contains 100 periods of $63 \AA$ Ti and $40 \AA$ NiTi. The Ti layers are crystalline with a $(00.1)$ fiber texture while the NiTi layers are amorphous. The $(00.1) \mathrm{Ti}$ planes are lattice imaged in this micrograph. The grazing incidence thermal neutron reflectivity of this multilayer microstructure superlattice was measured to be $>95 \%$ using tacilities at the National Institute for Science and Technology. Model calculations predict thermal neutron reflectivities of $\sim 99.6 \%$ as the neutron optical constants of $\mathrm{Ti}$ and $\mathrm{Ni}$ are very well suited to this application. The micrograph was taken by Mark A. Wall of Lawrence Livermore National Laboratory using a top-entry JEOL $200 \mathrm{CX}$ transmission electron microscope at the National Center for Electron Microscopy, Lawrence Berkeley Laboratory. 
Materials Research Society • 9800 McKnight Road • Pittsburgh, PA 15237

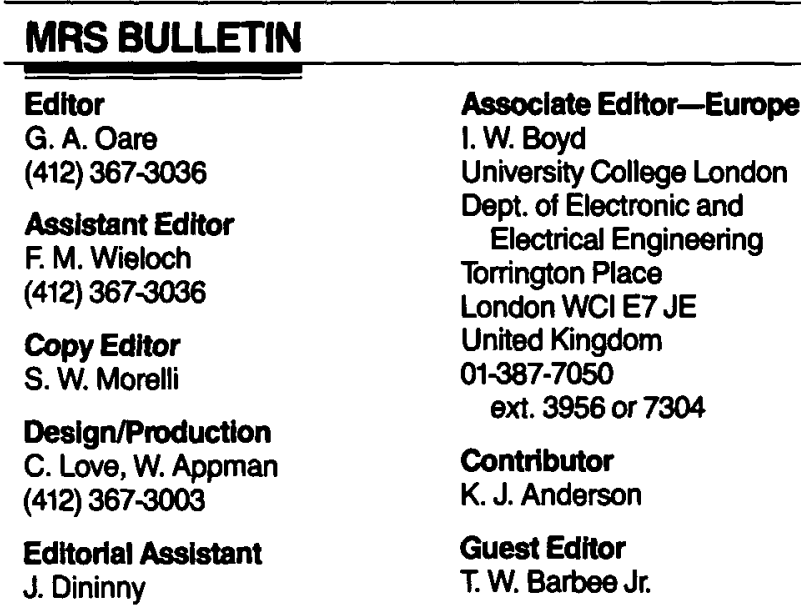

(412) $367-3036$

Advertising and Circulation

M. E. Kaufold

(412) $367-3036$

\section{MRS EXECUTIVE COMMITTEE}

\begin{tabular}{ll}
\hline President & Secretary \\
R. R. Chianelli & C.M. Jantzen \\
Exxon Research & Westinghouse Savannah \\
and Engineering & \multicolumn{1}{c}{ River Co. } \\
First Vice President and & Treasurer \\
President-Elect & S. M. Kelso \\
J. B. Roberto & Therma-Wave, Inc. \\
Oak Ridge National & Immediate Past President \\
Laboratory & R. P. H. Chang \\
Second Vice President & Northwestem University \\
S. Cargill & \\
IBM T.J. Watson & \\
Research Center & \multicolumn{2}{c}{ Executive Director } \\
Materials Research Society \\
John B. Ballance
\end{tabular}

\section{P. Siffert}

Centre de Recherches Nucléaires

Laboratoire PHASE

67037 Strasbourg, Cedex, France

Telephone: (88) 286543

Fax: (88) 280990
Chairman-Editorial Boards

E. N. Kaufmann

Argonne National Laboratory

Argonne, Illinois

International Advisory Board

M. Balkanski

R. Roy

University of Pierre and Marie Curie Pennsytvania State University

Paris, France University Park, Pennsytvania

S. Hsu

Chung Shan Institute of Science

and Technology

Taiwan, China

G. D.W. Smith

University of Oxford

Oxford, United Kingdom

R. Krishnan

Defense Research and

Development Organization

New Delhi, India

H. D. Li

Tsinghua University

Beijing, China

T. Sugano

University of Tokyo

Tokyo, Japan

J.S. Williams

Royal Melbourne Institute of

Technology

Melbourne, Australia

Technical Editorial Board

J. C. C. Fan

Kopin Corporation

Taunton, Massachusetts

F. Y. Fradin

Argonne National Laboratory

Argonne, Illinois

G. L. Liedl

Purdue University

West Lafayette, Indiana

R. L. Schwoebel

Sandia National Laboratories

Albuquerque, New Mexico

S. Namba

Osaka University

Osaka, Japan

MRS BULLETIN

Publications Subcommittee

M. H. Bennett-Lilley

R. C. SundahI

Intel Corporation

Chandler, Arizona

Texas Instruments

K. C. Taylor

General Motors

Dallas, Texas

P. Sliva

General Electric

R. R. Chianelli

Exxon Research and Engineering AT\&T Bell Laboratories

Annandale, New Jersey Murray Hill, New Jersey

R. J. Eagan

Sandia National Laboratories Oak Ridge National Laboratory

Albuquerque, New Mexico
C. W. White

Oak Ridge, Tennessee

\section{ABOUT THE MATERIALS RESEARCH SOCIETY}

The Materials Research Society (MRS) is a nonprofit scientific association founded in 1973 to promote interdisciplinary goatoriented basic research on materials of technological importance. Membership in the Society includes more than 9,500 scientists from industrial, government, and university research laboratories in the United States and more than 25 countries.

The Society's interdisciplinary approach to the exchange of technical information is qualitatively different from that provided by single-discipline professional societies because it promotes technical exchange across the various fields of science affecting materials development. MRS sponsors two major international annual meetings encompassing approximately 40 topical symposia, as well as numerous single-topic scientific meetings each year. It recognizes professional and technical excellence, conducts short courses, and fosters technical exchange in various local geographic regions through Section activities and University Chapters.

MRS is an Affiliated Society of the American Institute of Physics and participates in the international arena of materials research through associations

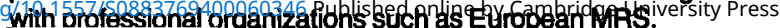

MRS publishes symposium proceedings, the MRS BULLETIN, Jouma/ of Materials Research, and other current scientific developments.

MRS BUULTIN (ISSN: 0883-7694) is published 12 times a year by the Materials Research Society, 9800 McKnight Road, Pittsburgh, PA 15237. Membership in MRS includes $\$ 25.00$ ( $\$ 15.00$ for students) from membership dues to be applied to a subscription to the MRS BULLETIN. Application to mail at second class rates is pending at Pittsburgh, PA and at additional mailing offices. POSTMASTER: Send address changes to MRS BULLETIN in care of the Materials Research Society, 9800 McKnight Road, Pittsburgh, PA 15237; telephone (412) 367-3003; fax (412) 367-4373.

Back volumes of this publication are available in $16 \mathrm{~mm}$ microfilm, $35 \mathrm{~mm}$ microfilm, or $105 \mathrm{~mm}$ microfiche through University Microfilms Inc., 300 North Zeeb Road, Ann Arbor, Michigan 48106. 
